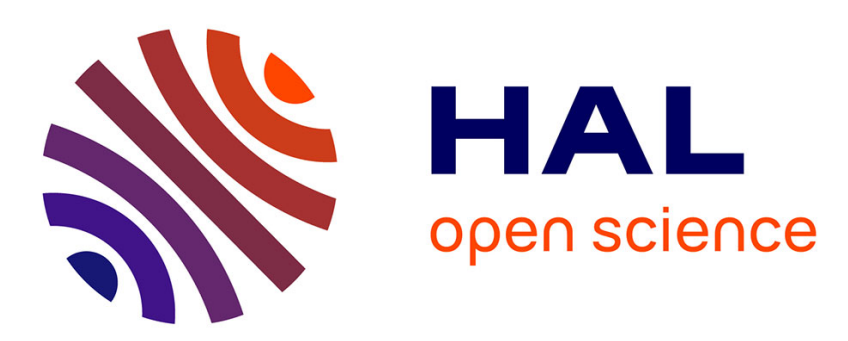

\title{
Structural and optical characteristics of Er-doped SRSO layers deposited by the confocal sputtering technique
}

Khalil Hijazi, Larysa Khomenkova, Julien Cardin, Fabrice Gourbilleau, Richard Rizk

\section{- To cite this version:}

Khalil Hijazi, Larysa Khomenkova, Julien Cardin, Fabrice Gourbilleau, Richard Rizk. Structural and optical characteristics of Er-doped SRSO layers deposited by the confocal sputtering technique. Physica E: Low-dimensional Systems and Nanostructures, 2009, 41, pp.1067-1070. 10.1016/j.physe.2008.08.048 . cea-02415354

HAL Id: cea-02415354 https://hal-cea.archives-ouvertes.fr/cea-02415354

Submitted on 17 Dec 2019

HAL is a multi-disciplinary open access archive for the deposit and dissemination of scientific research documents, whether they are published or not. The documents may come from teaching and research institutions in France or abroad, or from public or private research centers.
L'archive ouverte pluridisciplinaire HAL, est destinée au dépôt et à la diffusion de documents scientifiques de niveau recherche, publiés ou non, émanant des établissements d'enseignement et de recherche français ou étrangers, des laboratoires publics ou privés. 


\title{
Structural and optical characteristics of Er-doped SRSO layers deposited by the confocal sputtering technique
}

\author{
K. Hijazi, L. Khomenkova, J. Cardin, F. Gourbilleau*, R. Rizk \\ CIMAP, UMR CNRS/CEA/ENSICAEN/Université de Caen, 6 Bd. Marechal Juin, 14050 Caen Cedex, France
}

\begin{abstract}
A B S T R A C T
Er-doped silicon-rich silicon oxide layers have been grown at $600^{\circ} \mathrm{C}$ by magnetron co-sputtering of three confocal cathodes $\left(\mathrm{Si}, \mathrm{SiO}_{2}\right.$ and $\left.\mathrm{Er}_{2} \mathrm{O}_{3}\right)$ in pure argon plasma. The structural and optical properties of the layers were examined in the function of deposition and annealing conditions. It was shown that the increase of the RF power density applied on the $\mathrm{Si}$ cathode from 0.74 to $2.07 \mathrm{~W} \mathrm{~cm}^{-2}$, while maintaining constant RF power on the two other cathodes, allows a fine engineering of the Si excess from 5 to 15 at\%. The Er content was evaluated to $1 \times 10^{21} \mathrm{at} \mathrm{cm}^{-3}$. A high $\mathrm{Er}^{3+}$ emission was observed under non-resonant $(476 \mathrm{~nm})$ excitation from as-deposited layers, which was significantly improved after annealing at $600^{\circ} \mathrm{C}$. The Er PL was found to be much more intense than the best samples reported so far, which was annealed at $900{ }^{\circ} \mathrm{C}$ and contains, however, lower Er content $\left(5.4 \times 10^{20}\right.$ at cm $\left.^{-3}\right)$ and Si excess ( 7 at\% of Si). The Er emission lifetime was found to be about $6 \mathrm{~ms}$ for low Si excess ( 5 at\%) and $1-2 \mathrm{~ms}$ for high $\mathrm{Si}$ excess. Upon reducing the Er content by a factor of three, the $\mathrm{Er}^{3+} \mathrm{PL}$ intensity was further increased and the lifetime reached $5.5 \mathrm{~ms}$, suggesting a notable increase of the fraction of coupled Er ions.
\end{abstract}

Reactive magnetron sputtering

Erbium

Si nanocluster

Photoluminescence

\section{Introduction}

The emission at $1.54 \mu \mathrm{m}$ related to the ${ }^{4} \mathrm{I}_{13 / 2} \rightarrow{ }^{4} \mathrm{I}_{15 / 2}$ internal transitions of Er ions plays an important role in the development of telecommunications, because of its minimum absorption by silica, which is widely used in Er-doped fiber amplifiers [1]. However, Er-doped silica suffers from two limitations: a low excitation cross-section of $\operatorname{Er}\left(\sim 5 \times 10^{-21} \mathrm{~cm}^{2}\right.$ at $\left.1.54 \mu \mathrm{m}\right)[2]$ and a low solubility that induces Er clustering with the concentrationrelated detrimental effects [3]. To improve both Er excitation and device packaging, a great effort has been devoted since several years to benefit from the broad-band high-absorbing Si nanoclusters ( $\mathrm{Si}-\mathrm{nc}$ ) as sensitizers of the neighboring Er ions in silicon-rich silicon oxide (SRSO) [4-7]. This allows the enhancement of the effective excitation of Er ions by 3-4 orders of magnitude and the use of high-power LEDs or electrical excitation instead of the expensive pump lasers. Such an approach seems promising for the development of compact Er-doped waveguide amplifiers (EDWAs). The achievement of a net gain in EDWAs has been thwarted so far by two main difficulties: the reduction of the carrier absorption found responsible for the main losses [8] and the necessity of enhancing the low number of Er coupled to Si-nc

\footnotetext{
* Corresponding author. Tel.: +3323145 2656; fax: +33231452660.

E-mail address: fabrice.gourbilleau@ensicaen.fr (F. Gourbilleau).
}

estimated recently to a few \% [9,10]. To overcome these issues, a careful engineering of both composition and morphology of the material is necessary to grow very small Si-nc with high density. Their smallness is expected to minimize the confined carrier absorption effect [11], while their high density is liable to couple an optimum concentration of Er ions.

This paper deals with a novel approach for our team aiming at allowing the optimization of $\mathrm{Si}$ excess for the growth of appropriate Si-nc density that ensures the coupling with maximum Er ions.

\section{Experiment}

The Er-SRSO layers were grown by the magnetron co-sputtering of three cathodes, namely $\mathrm{SiO}_{2}$, $\mathrm{Si}$ and $\mathrm{Er}_{2} \mathrm{O}_{3}$, under a plasma of pure argon maintained at a pressure of $3 \mathrm{mTorr}$. The RF power density applied on the Si cathode $\left(P_{\mathrm{Si}}^{\mathrm{RF}}\right)$ was changed from 0.74 to $2.07 \mathrm{~W} \mathrm{~cm}^{-2}$ to vary the $\mathrm{Si}$ excess incorporated, while for the $\mathrm{SiO}_{2}$ and $\mathrm{Er}_{2} \mathrm{O}_{3}$ targets they were fixed at 7.4 and $0.74 \mathrm{~W} \mathrm{~cm}^{-2}$, respectively. The depositions were made at $T_{\mathrm{S}}=600{ }^{\circ} \mathrm{C}$ on a rotating substrate, hence ensuring good homogeneity of both composition and thickness. The latter was in the range $1-1.5 \mu \mathrm{m}$. The deposited films were subsequently annealed under a nitrogen flux, for $1 \mathrm{~h}$ at different temperatures, $T_{\mathrm{a}}$, between 600 and $800^{\circ} \mathrm{C}$. To investigate the structural and configurational properties, 
Fourier transform infrared (FTIR) spectra were recorded under Brewster incident $\left(65^{\circ}\right)$, using a Nicolet Nexus spectrometer. Energy dispersive X-ray spectroscopy (EDX) was used to determine the Er content, which was found close to $10^{21} \mathrm{~cm}^{-3}$ for all samples. The refractive index and thickness of the layers were obtained by M-lines measurements performed in reflection configuration [12-14]. These measurements were made by means of a He-Ne laser operating at $632.8 \mathrm{~nm}(1.95 \mathrm{eV})$ polarized in the transverse electric (TE) mode. The optical properties were examined by PL measurements using two excitation lines, the resonant $488 \mathrm{~nm}$ and non-resonant $476 \mathrm{~nm}$ delivered by an $\mathrm{Ar}^{+}$ laser. The pumping at $476 \mathrm{~nm}$ was used to ensure that Er emission was stimulated by the energy transfer from the Si-nc sensitizers. The Er PL was measured with a Jobin Yvon $1 \mathrm{~m}$ single grating monochromator and Northcoast Germanium detector cooled with liquid nitrogen. The PL signal was recorded through an SRS lock-in amplifier (SP830 DPS) referenced to the chopping frequency of light of $20 \mathrm{~Hz}$. The time-resolved Er PL was measured with the already-described PL system, the signal being displayed by a Tektronix oscilloscope (TDS 3012B).

\section{Results and discussion}

Fig. 1 shows the FTIR spectra recorded on the samples deposited at $600{ }^{\circ} \mathrm{C}$ with different $P_{\mathrm{Si}}^{\mathrm{RF}}$ values before being annealed at $600^{\circ} \mathrm{C}$. The FTIR spectrum corresponding to the layer prepared at $P_{\mathrm{Si}}^{\mathrm{RF}}=0$ with the same conditions but free from $\mathrm{Si}$ excess, i.e. silica film deposited at $600^{\circ} \mathrm{C}$, is also shown for comparison. All the spectra were acquired at Brewster incident to avoid any reflection and detect the longitudinal optical $\left(\mathrm{LO}_{3}\right)$ mode associated with the $\mathrm{Si} / \mathrm{SiO}_{2}$ interface at $1250 \mathrm{~cm}^{-1}$ [15], and then normalized with respect to the transversal optic $\left(\mathrm{TO}_{3}\right)$ mode at about $1080 \mathrm{~cm}^{-1}$. By increasing the $P_{\mathrm{Si}}^{\mathrm{RF}}$ value, one notices a gradual merging of the doublet $\mathrm{TO}_{4}-\mathrm{LO}_{4}$ located around $1160-1200 \mathrm{~cm}^{-1}$, which occurs apparently at the expense of the $\mathrm{LO}_{3}$ peak, which shows a progressive decrease. Such a merging reflects some increase of the disorder [16] that can be merely attributed to the increasing amount of the Si excess, expected to take place when $P_{S i}^{R F}$ is increased. It is worth noting that the evolution of the $\mathrm{LO}_{3}$ mode is much more governed by the disorder than by the behavior of the $\mathrm{Si} / \mathrm{SiO}_{2}$ interface, since the annealing

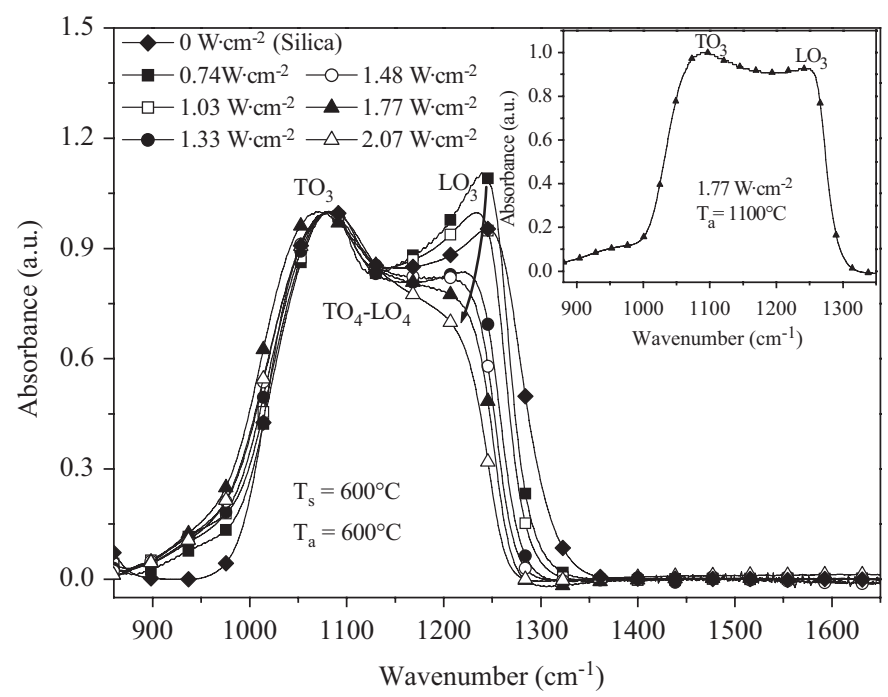

Fig. 1. FTIR spectra of the samples annealed at $600{ }^{\circ} \mathrm{C}$ and previously deposited at $600{ }^{\circ} \mathrm{C}$ with the indicated values of the power density applied on the Si target. The inset shows the FTIR spectrum for the sample deposited with $P_{\mathrm{Si}}^{\mathrm{RF}}$ density $=1.77$ $\mathrm{W} \mathrm{cm}{ }^{-2}$ and annealed at $1100{ }^{\circ} \mathrm{C}$. temperature $\left(600^{\circ} \mathrm{C}\right)$ is too low to grow Si-nc but might induce the formation of some 'atomic' scale sensitizers [17]. The 'usual' Si-nc sensitizers are rather grown at much higher temperatures in such a material $[17,18]$, giving rise to a signature of the $\mathrm{Si} / \mathrm{SiO}_{2}$ interface, as shown by the FTIR spectrum reported in the inset for a sample containing 14 at\% of Si excess and annealed at $1100{ }^{\circ} \mathrm{C}$. Indeed, the signature of the $\mathrm{Si} / \mathrm{SiO}_{2}$ interface appears more pronounced than that for the case of annealing at $600{ }^{\circ} \mathrm{C}$, and then attest the formation of Si-nc, even though the high level of $\mathrm{LO}_{4}-\mathrm{TO}_{4}$ still reflects the important disorder of the host matrix attributed to the high values of both Si excess and Er content. To better correlate this power $P_{\mathrm{Si}}^{\mathrm{RF}}$ density to the $\mathrm{Si}$ excess, we have proceeded to a rough estimate of their amount in substoichiometric $\mathrm{SiO}_{x}$ from the FTIR spectra by the method described in Ref. [19]. One can observe a gradual increase of the Si excess from about 5 to about 15 at\% when the $P_{S i}^{\mathrm{RF}}$ density increases from 0.74 to $2.07 \mathrm{~W} \mathrm{~cm}^{-2}$ (Fig. 2). Such an evolution was also confirmed for other series of samples obtained with different $T_{\mathrm{S}}$ values (not shown here).

The progressive increase of the $\mathrm{Si}$ excess with the power density is also reflected by the concomitant evolution of the refractive index $n$, as determined by M-lines measurements. Indeed, $n$ increases with the $\mathrm{Si}$ excess, which was roughly estimated by the FTIR-based approach, as already specified.

Concerning the emission properties, Fig. 3 compares the evolution of the PL intensity at $1.54 \mu \mathrm{m}$ as a function of the photon flux of a non-resonant line $(476 \mathrm{~nm})$, for three samples: the reference sample (R) obtained using the previous method consisting the reactive sputtering of a single $\mathrm{SiO}_{2}$ cathode topped by $\mathrm{Er}_{2} \mathrm{O}_{3}$ chips, as previously described [11,18,20], and the asdeposited and annealed samples obtained by the magnetron cosputtering of three confocal cathodes, described above. The reference $\mathrm{R}$ contains 7 at\% $\mathrm{Si}$ and $5.4 \times 10^{20} \mathrm{Ercm}^{-3}$ and was annealed at $900{ }^{\circ} \mathrm{C}$ during $10 \mathrm{~min}$, while the present samples contain 10 at\% Si and $1 \times 10^{21} \mathrm{Er} \mathrm{cm}^{-3}$ with one annealed at only $600{ }^{\circ} \mathrm{C}$ during $1 \mathrm{~h}$. It is important to note that the PL intensity increases for the three samples when the photon flux is increased between $2 \times 10^{18}$ and $7 \times 10^{19} \mathrm{ph} \mathrm{cm}^{-2} \mathrm{~s}^{-1}$. In this flux range, the impact of the up-conversion process on our annealed sample, which shows a quasi-linear increase, is much weaker than that on the reference sample, and can be therefore considered as a nonlimiting factor. Anyway, all along the flux range, the PL intensity of the as-deposited sample is higher than that for the $\mathrm{R}$ layer, and this PL emission is further improved for the sample annealed at a temperature as low as $600^{\circ} \mathrm{C}$. The inset compares the PL spectra

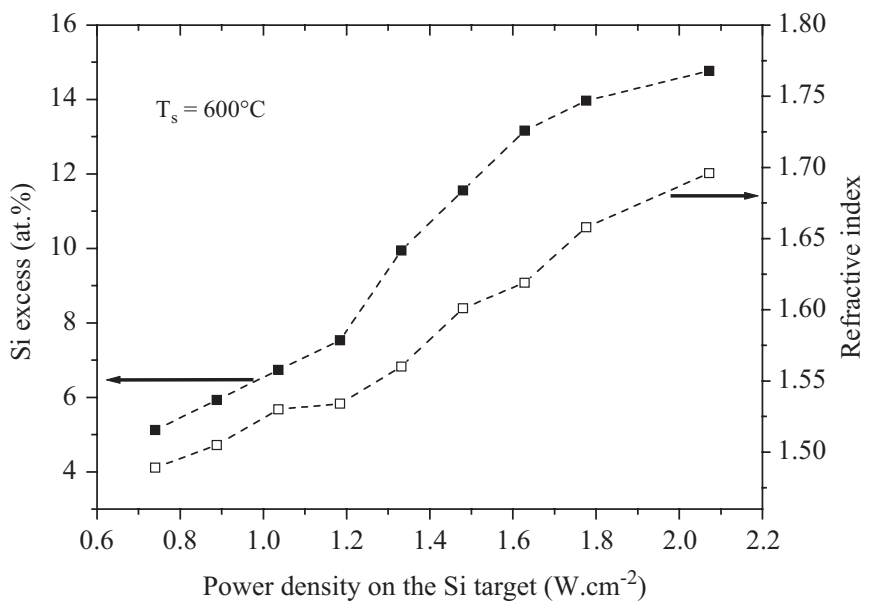

Fig. 2. Variation of the Si excess, as estimated from the FTIR spectra, and evolution of the refractive index obtained by M-lines measurements, in function of the power density applied on the Si target. 


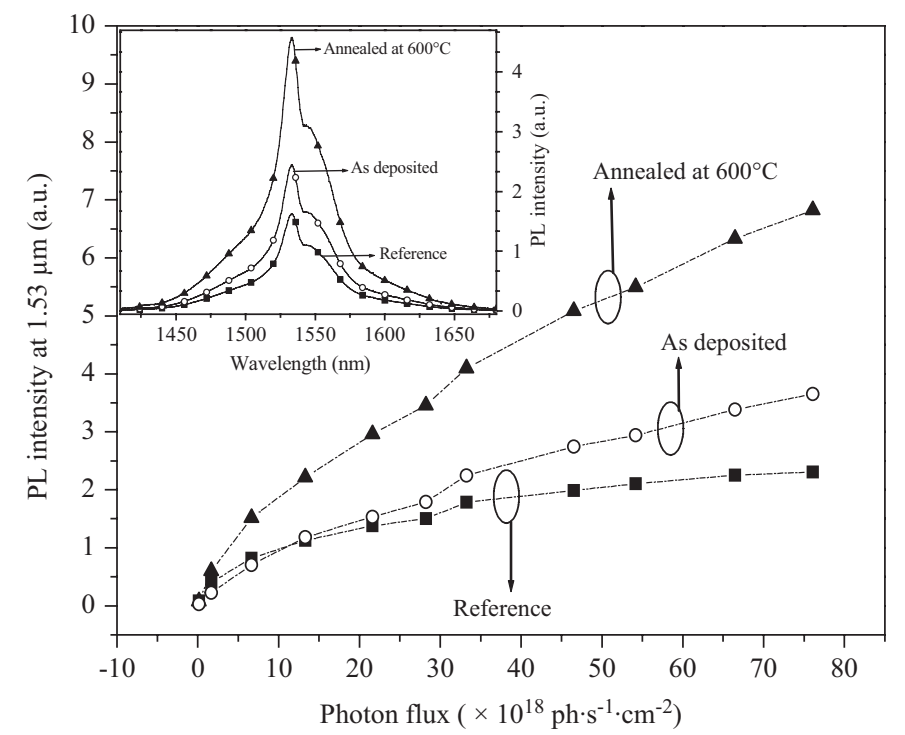

Fig. 3. Comparison of the PL intensity at $1.54 \mu \mathrm{m}$ recorded with a non-resonant $(476 \mathrm{~nm})$ line on the reference sample $(\mathrm{R})$ (see text) and on the present samples: as-deposited and annealed at $600{ }^{\circ} \mathrm{C}$. The inset reports the PL spectra for the reference sample (R) and the two as-deposited and annealed (at $600{ }^{\circ} \mathrm{C}$ ) samples for a photon flux of about $6 \times 10^{19} \mathrm{ph} \mathrm{cm}^{-2} \mathrm{~s}^{-1}$.

obtained on the as-deposited and annealed (at $600{ }^{\circ} \mathrm{C}$ ) samples to that of the reference sample (R), under a non-resonant $476 \mathrm{~nm}$ excitation line with a flux of about $6 \times 10^{19} \mathrm{ph} \mathrm{cm}^{-2} \mathrm{~s}^{-1}$. It is worth noting that the $1.53-\mu \mathrm{m}$ PL intensity from the as-deposited sample is nearly 1.5 times higher than that from the R layer. This PL emission was further improved by a factor $\sim 3$ after annealing at $600{ }^{\circ} \mathrm{C}$. The detection of PL from the as-deposited layer, never or rarely observed from as-grown samples, is likely due to the high deposition temperature $\left(600^{\circ} \mathrm{C}\right)$, which seems to favor, during the growth, the formation of some sensitizers, which could be compared to the already mentioned 'atomic' scaled sensitizers described in Ref. [17]. Nevertheless, due to their poor contrast and their small size, such agglomerates have not been successfully evidenced by high-resolution electron microscopy [17]. The annealing at $600^{\circ} \mathrm{C}$ allows the recovery of non-radiative defects and/or the relaxation of the matrix network, leading to some improvement of Er PL.

Fig. 4(a) shows the evolution of the PL intensity at $1.54 \mu \mathrm{m}$ for the indicated annealing temperatures as a function of Si excess estimated from the analysis of FTIR spectra. During the first stages of increase of Si excess, the Er PL shows a gradual improvement for the as-deposited and all annealed samples, up to a maximum corresponding to about 10 at\% of Si excess, before decreasing for higher values of Si excess. The highest PL is shown by the samples annealed at $600{ }^{\circ} \mathrm{C}$, all over the range of $\mathrm{Si}$ excess, hence generalizing the performance of that similarly annealed and enriched with 10 at\% of $\mathrm{Si}$, as displayed in Fig. 3. This observation supports our earlier suggestion of the occurrence of the highest Er-Si-nc coupling for $T_{\mathrm{a}}=600^{\circ} \mathrm{C}$. The same explanation can still be valid for the evolution of the PL shown in Fig. 4(a). For a constant concentration of Er, the coupled fraction is expected to increase with the Si excess, up to an optimum value corresponding to a maximum density of sensitizers Si-nc growing/aggregating on the seeds available in a given sample. When the value of Si excess exceeds a given value, one expects some saturation of the available seeds, leading to an increase of the average size of the Si-nc at the expense of their efficiency as sensitizers and/or their density in case of coalescence. Anyway, beyond a given value, the impact of $\mathrm{Si}$ excess becomes detrimental to the quality of the

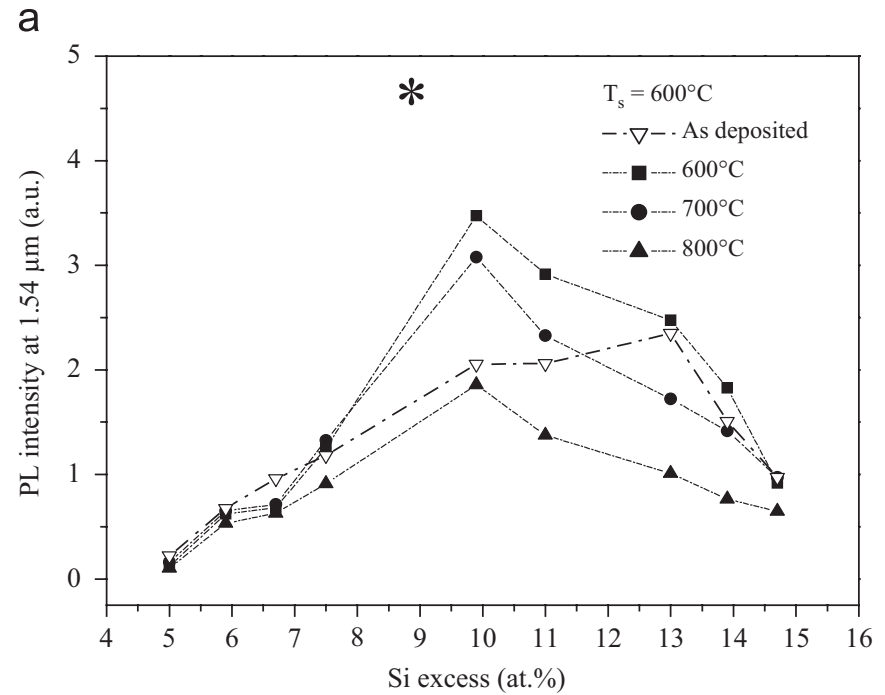

b

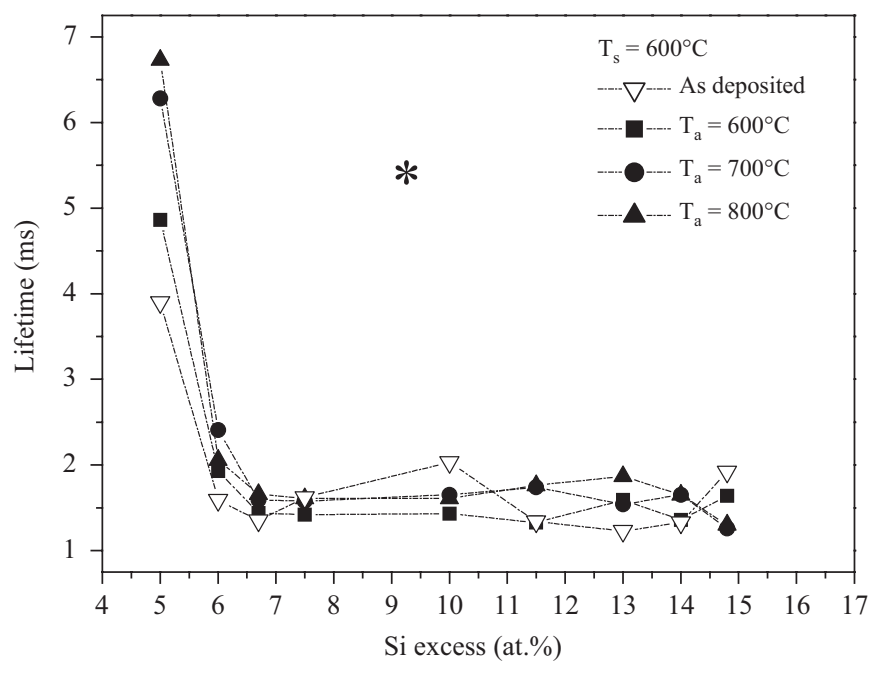

Fig. 4. (a): The PL intensity at $1.54 \mu \mathrm{m}$ as a function of the Si excess with nonresonant excitation $(\lambda=476 \mathrm{~nm})$, for the as-deposited and annealed samples at the indicated temperature. (b): Evolution of the emission lifetime for the samples of Fig. 4(a) against the Si excess. The two experimental points labeled by $\left(^{*}\right)$ for the PL intensity and lifetime were obtained for the sample containing lower Er content than those of the main plots $\left(3.5 \times 10^{20}\right.$ vs. $\left.10^{21} \mathrm{at} \mathrm{cm}^{-3}\right)$ and a $\mathrm{Si}$ excess of about 9 at\%.

matrix, as confirmed by the evolution of the doublet $\mathrm{TO}_{4}-\mathrm{LO}_{4}$. (Fig. 1). Concerning the emission properties, the lifetime shows a dramatic deterioration from a value higher than $6 \mathrm{~ms}$ for a $\mathrm{Si}$ excess of about 5 at\% to $1-2 \mathrm{~ms}$ when the $\mathrm{Si}$ excess is higher than 7 at\%, as displayed in Fig. 4(b). Nevertheless, one has to note that the Er concentration of $10^{21} \mathrm{at} \mathrm{cm}^{-3}$ is relatively high compared to that for the R sample and could also be one of the reasons for the observed improvement in the PL intensity. Moreover, such a high concentration is expected to generate, for high fluxes, cooperation up-conversion phenomena and other concentration quenchings, which are also harmful for both coupling/emission efficiency and lifetime. To counter these, a series of samples have been lately prepared with $3.5 \times 10^{20} \mathrm{Er} \mathrm{cm}^{-3}$. A typical preliminary result is reported for a sample containing also an optimum Si excess ( $~ 9$ at\%). The corresponding data for the Er PL intensity and emission lifetime are labeled by stars in Fig. 4(a) and (b). One can notice that, in addition to some $25 \%$ improvement of the Er PL, the emission lifetime has been significantly increased from 1 to $2 \mathrm{~ms}$ for the present samples to about $5.5 \mathrm{~ms}$ for those under studies. 
Since this sample contains an Er content comparable to that for the reference layer, the observed improvement of its PL intensity reflects in all likelihood a consequent increase in the fraction of coupled Er ions. Anyway, the work is in progress for further optimization of both Si excess and Er content.

\section{Conclusion}

In conclusion, we have fabricated a series of samples with different $\mathrm{Si}$ excess by magnetron co-sputtering of three confocal cathodes that were subsequently characterized by different techniques. Both as-deposited (at $600^{\circ} \mathrm{C}$ ) and annealed samples showed Er PL intensity much higher compared to the 'standard' sample previously described in Refs. [10,11]. The maximum Er PL was obtained for the sample annealed at $600^{\circ} \mathrm{C}$ for $1 \mathrm{~h}$ and containing 10 at\% of $\mathrm{Si}$ excess with a lifetime of $1-2 \mathrm{~ms}$. By reducing the disadvantageous high $\mathrm{Er}$ content $\left(\sim 10^{21} \mathrm{at} \mathrm{cm}^{-3}\right)$ responsible fro detrimental concentration-related effects, by a factor of three, the PL intensity was further improved and the lifetime enhanced to about $5.5 \mathrm{~ms}$. This might suggest an increasing proportion of the Er ions coupled to Si-nc.

\section{Acknowledgment}

This work was supported by the European Community through the Project LANCER (FP6-IST-033574).

\section{References}

[1] E. Desurvire, J.R. Simpson, P.C. Pecker, Opt. Lett. 12 (1987) 888.

[2] J. Miniscalco, J. Lightwave Technol. 9 (1991) 234

[3] A. Polman, J. Appl. Phys. 82 (1997) 1.

[4] A.J. Kenyon, P.F. Trwoga, M. Federighi, C.W. Pitt, J. Phys. 6 (1994) L319.

[5] M. Fujii, M. Yoshida, Y. Kanzawa, S. Hayashi, K. Yamamoto, Appl. Phys. Lett. 71 (1997) 1198.

[6] H. Przybylinska, W. Jantsch, Yu. Suprun-Belevitch, M. Stepikhova L. Palmetshofer, G. Hendorfer, A. Kozanecki, Phys. Rev. B 54 (1996) 2532.

[7] G. Franzò, V. Vinciguerra, F. Priolo, Appl. Phys. A: Mater. Sci. Process 69 (1999)

[8] N. Daldosso, D. Navarro-Urrios, M. Melchiorri, L. Pavesi, F. Gourbilleau, M. Carrada, R. Rizk, C. Garcia, P. Pellegrino, B. Garrido, L. Cognolato, Appl. Phys. Lett. 86 (2005) 261103.

[9] M. Wojdak, M. Klik, M. Forcales, O.B. Gusev, T. Gregorkiewicz, D. Pacifici, G. Franzò, F. Priolo, F. Iacona, Phys. Rev. Lett. 69 (2004) 233315.

[10] B. Garrido, C. García, S.-Y. Seo, P. Pellegrino, D. Navarro-Urrios, N. Daldosso, L. Pavesi, F. Gourbilleau, R. Rizk, Phys. Rev. B 76 (2007) 245308.

[11] N. Daldosso, D. Navarro-Urrios, M. Melchiorri, C. Garcia, P. Pellegrino, B. Garrido, C. Sada, G. Battaglin, F. Gourbilleau, R. Rizk, L. Pavesi, IEEE J. Sel. Top. Quantum Electron. 12 (2006) 1607.

[12] R.T.H. Kersten, J. Mod. Opt. 22 (1975) 503.

[13] R. Ulrich, R. Torge, Appl. Opt. 12 (1973) 2901.

[14] J. Cardin, D. Leduc, Appl. Opt. 47 (2008) 894

[15] J.E. Olsen, F. Shimura, J. Appl. Phys. 66 (1989) 1353.

[16] T. Kirk, Phys. Rev. B 38 (1988) 1255.

[17] O. Savchyn, F.R. Ruhge, P.G. Kik, R.M. Todi, K.R. Coffey, H. Nukala, H. Heinrich, Phys. Rev. B 76 (2007) 195419.

[18] F. Gourbilleau, C. Dufour, M. Levalois, J. Vicens, R. Rizk, C. Sada, F. Enrichi, G. Battaglin, J. Appl. Phys. 94 (2003) 3896.

[19] F. Yun, B.J. Hinds, S. Hatatani, S. Oda, Q.X. Zhao, M. Willander, Thin Solid Films 375 (2000) 137.

[20] F. Gourbilleau, M. Levalois, C. Dufour, J. Vicens, R. Rizk, J. Appl. Phys. 95 (2004) 3717. 